\title{
BRONCHIAL ASTHMA AND OBESITY IN CHILDHOOD
}

\author{
Jana Kryštofová, Miloš Jeseňák, Peter Bánovčin
}

Comenius University in Bratislava, Jessenius Medical Faculty, University Hospital Martin, Department of Pediatrics, Slovak Republic

Summary: Bronchial asthma and obesity is among a group of multietiologic complex diseases which influence each other in their origin, and development. The impact on the patient's quality of life and prognosis is significant, health costs included. Because of the increasing prevalence worldwide, there has been an increase in the amount of studies dealing with reciprocal associations between asthma and obesity.

Key words: Asthma; Obesity; BMI; Children

\section{Introduction}

Obesity in children has become a serious health problem worldwide because of its rising tendency in this age group and its health consequences later in life. It is hard to answer the question concerning when a child can be diagnosed as obese according to the proportion of the body fat. The proportion of the body fat changes with development and this change depends not only on the child's age but gender as well. The proportion of body fat usually increases in the first year of life and then decreases until six years of age, and then rises again. With time, we observe a decrease once again (Burniat 1997) and at the end of the development the value ranges between $23-26 \%$ in girls and $11-17 \%$ in boys. According to Herold (1999), adiposity is defined by the proportion of body fat exceeding $30 \%$ in adult women and $20 \%$ in adult men (22). Some investigators refer to children and adolescents as overweight, obese, or morbidly obese if their weight exceeds what is expected for their height by $20 \%$, $50 \%$, and $80-100 \%$, respectively. The body mass index (BMI) has not been consistently used or validated in children younger than 2 years of age. Because weight varies in a continuous rather than a gradual way, the use of these arbitrary criteria is problematic and may be misleading. Nevertheless, children and adolescents defined as overweight or obese according to the published criteria are likely to maintain this ponderal status as adults (37).

\section{Epidemiology}

Asthma, like obesity, has multiple negative influences on the patient's quality of life. For the prevention of both it is important to observe their tendencies. About $20 \%$ of children and adolescents are overweight, and a third of these are obese. The prevalence of obesity is rising rapidly and is expected to include 150 million adults and 15 million children by 2010 . The trend in obesity is especially alarming in children and adolescents. The annual rate of increase in the prevalence of childhood obesity has been growing steadily, and the current rate is 10 times that in the 1970s (5). The prevalence of asthma is almost twice as high in obese versus normal weight women, but not in obese men (24). In 1999-2004, asthma prevalence in children across the European study centres varied from less than $5 \%$ to over $20 \%$. The highest prevalences of asthma symptoms in children aged 6-7 years $(>20 \%)$ and $13-14$ years $(>25 \%)$ were found in Ireland and the United Kingdom. The lowest asthma rates for both age groups were found in Albania (<5\%) (38). Asthma incidence increases by $50 \%$ in overweight/obese individuals (4).

\section{Obese asthmatic}

Many studies describe differences between obese asthmatics and normal weight asthmatics. Obese adults are more likely than those with normal BMIs $\left(<25 \mathrm{~kg} / \mathrm{m}^{2}\right)$ to report poor asthma-specific quality of life (odds ratio [OR], 2.8; 95\% CI, 1.6-4.9), poor asthma control (OR, 2.7; 95\% CI, 1.7-4.3), and a history of asthma-related hospitalizations (31). Obese people with asthma are 2.5 times more likely to experience shortness of breath (dyspnea), have a higher use of inhalers and medications to increase airflow (bronchodilators), and require longer stays in hospital emergency units compared to non-obese people with asthma. Being overweight has been shown to double the risk for airway hyperreactivity, while obesity increases the risk 2.7-fold, independent of age or gender (11). Obese asthmatics have lower lung function and more co-morbidities compared to normal weight asthmatics $(32,34)$. However, in older infants and all older paediatric age groups assessing body weight for the body height (length) is recommended. This is the globally preferred assessment, preferred over assessing body weight according to age. The arbitrary range of eutrophia can be delimited between the 25 th and 75 th percentile of the weight to height ratio $(\mathrm{W} / \mathrm{H})$. Body weight values less 
then the 20th percentile $\mathrm{W} / \mathrm{H}$ belong to the zone of "underweight". When in the 10th percentile below $\mathrm{W} / \mathrm{H}$, we are speaking about significant hypotrophy. Medical attention is also needed in individuals with a body weight higher than the 80th percentile in the weight to height ratio (=overweight). Being in the 85 th percentile above $\mathrm{W} / \mathrm{H}$ is most likely considered obesity. Considering the large number of diseases, it is important to specify the body weight in order to obtain an orientational evaluation of the body composition, i.e. to determine the proportions of the bone, muscle and fat making up the body weight (20).

\section{Associations between obesity and bronchial asthma}

Some of the studies in obese asthmatics have tried to find out which disease came first: asthma or obesity? This question remains unclear, but the reciprocal impact of both is evident. Several evident biologic mechanisms exist between asthma and obesity, leading to both direct or indirect association.

\section{Mechanical factors}

In the obese, the functional residual capacity (FRC) is reduced because of changes in the elastic properties of the chest wall. The retractive forces of the lung parenchyma on the airways are reduced at low lung volumes, and a lower FRC may unload the airway smooth muscle (ASM) so that it shortens more when activated either by normal parasympathetic tone, or by other bronchoconstricting agonists. Indeed, breathing at low lung volume has been shown to increase airway responsiveness. Importantly, small airway closure is observed in many obese subjects during tidal breathing, particularly in the supine posture. It has been suggested that the repeated opening and closing of peripheral airways that occurs under such circumstances may lead to rupture of alveolar attachments to bronchioles, uncoupling the airways from the retractive forces of the lung parenchyma, and exacerbating airway narrowing (35).

\section{Obesity and inflammation}

Adipose tissue is known to release a number of cytokines, including tumor necrosis factor- $\alpha$, interleukin-6 (IL-6), adiponectin and resistin, which have been shown to modulate local or systemic metabolism (30). Adipocytes are also endocrine organs, with multiple metabolic roles in regulating the whole-body physiology. Small adipocytes in lean individuals promote metabolic homeostasis; the enlarged adipocytes of obese individuals recruit macrophages and promote inflammation and the release of a range of factors that predispose individuals to insulin resistance (15). In obese humans, even in the absence of any overt inflammatory insult, there is chronic, low-grade systemic inflammation characterized by increased circulating leu- kocytes and increased serum concentrations of cytokines, cytokine receptors, chemokines, and acute phase proteins (Bullo et al., 2002, Straczkowski et al., 2002, Brunn et al., 2003b, Bullo et al., 2003, Esposito et al., 2003, Takahashi et al., 2003) (34). Many of these mediators are synthesized and secreted by cells from adipose tissue and have been given the generic name of adipokines. This group includes IL-6, IL-10, eotaxin, tumor necrosis factor- $\alpha$ (TNF- $\alpha)$, TGF- $\beta 1$, $\mathrm{C}$-reactive protein, leptin, and adiponectin (9). The cellular source of some of these factors appears to be macrophages that infiltrate obese adipose tissue (Weisberg et al., 2003, $\mathrm{Xu}$ et al., 2003) (34). TNF- $\alpha$ secretion is markedly increased in vitro from adipose tissue of obese subjects (25). TNF- $\alpha$ has been shown to be present in adipocytes and is directly related to body fat. Furthermore, TNF- $\alpha$ is known to be elevated in asthma and is linked to the production of Th2 cytokines (IL-4, IL-6) in bronchial epithelium, as a result of which higher TNF- $\alpha$ levels would lead to higher levels of these cytokines. TNF- $\alpha$ has been shown to be present in adipocytes and is directly related to body fat. Furthermore, TNF- $\alpha$ is known to be elevated in asthma and is linked to the production of Th2 cytokines (IL-4, IL-6) in bronchial epithelium, as a result of which higher TNF- $\alpha$ levels would lead to higher levels of these cytokines (9). Increased serum TNF- $\alpha$ in obesity is particulary interesting because TNF receptors (TNFRs) are expressed on airway smooth muscle. In these cells, exogenous TNF- $\alpha$ has been shown to increase calcium signaling to a variety of contractile agonists (Amrani a Panettieri, 1998). Exogenous TNF- $\alpha$ increases the expression of leptin, adiponectin, and IL-6 in cultured adipocytes (Kirchgessner et al., 1997, Kappes and Loffler, 2000, Fasshauer et al., 2002, Bruun et al., 2003, Fasshauer et al., 2003, Warne, 2003). Interestingly, the TNF- $\alpha$ gene lies within the asthma linkage regions on $6 \mathrm{p}$, and SNPs in TNF- $\alpha$ have been associated with both asthma and obesity (Tantisira and Weiss, 2001) (34). Serum levels of IL-6 are elevated in obese subjects and such levels have been associated with the severity of asthma (9). Higher circulating concentrations of IL- 6 have been positively associated with BMI, waist circumference, visceral fat accumulation as well as elevated triglycerides, plasma-free fatty acid levels, and systemic insulin. Obesity is also associated with increased plasma C-reactive protein, possibly through modulation by IL-6. Interestingly, weight loss is associated with a reduction in the macrophage infiltration of adipose tissue and an improvement in the inflammatory profile, including reduction in plasma IL-6 and C-reactive protein concentrations (30). Plasminogen activator inhibitor (PAI-1) is the most important endogenous inhibitor of tissue plasminogen activator and uro-plasminogen activator and is thus the major physiological inhibitor both of fibrinolysis and of plasmin activation (34). Recent studies suggest that PAI-1 may promote the development of asthma by regulating airway remodeling, airway hyper-responsiveness (AHR), and allergic inflammation (27). Adipocytes produce and secrete PAI-1 and serum levels of PAI-1 are increased in the obese and decrease with 
weight loss (van Harmelen et al., 2004, Vazquez et al., 2004). Increased serum PAI-1 could have effects in the airways that predispose towards hyper-responsiveness. Obesity-related increases in PAI-1 could provide such an imbalance by enhancing fibrin deposition, and by inhibiting the formation of plazmin, a major activator of matrix (34). A systematic increase in eotaxin has also been found in obese individuals (9). Eotaxin family (Eotaxin 1,2 and 3) recruits and activates CCR3-bearing cells such as eosinophil, mast cells, and Th2 lymphocytes, which play a major role in allergic disorders (21). Part of this chemokine is synthesized in adipocytes, and this suggests a potential role in the increased risk of asthma in obese patients (9). Asthmatic airways are characterized by enhanced oxidative stress, which can be studied by measuring biomarkers, such as 8 -isoprostane (7). Levels of 8-isoprostane and other markers of oxidative stress are increased both in the blood and the lungs of obese patients with asthma compared to lean patients and may also contribute to the relationship between obesity and asthma (35).

\section{Epigenetic influences}

Maternal diet may be a significant factor in the development of the fetal airway and immune system. As asthma is a complex disease of gene-environment interactions, maternal diet may play an epigenetic role in sensitizing fetal airways to respond abnormally to environmental insults (18). The variable natural history of asthma (i.e. incidence and remission of symptoms) may be a result of epigenetic changes such as DNA methylation, covalent histone modifications, microRNA changes and chromatin alterations following early or later environmental exposures. Methylation of DNA and resulting changes in chromatin structure have been shown to initiate the process by which the Th cells lose their plasticity and differentiate productively towards the Th1 versus the proallergic Th2 pattern of cytokine gene expression. A large body of research has implicated specific time periods when individuals seem to be more susceptible to the effects of environmental exposures and other asthma triggers. These include prenatal development, early childhood, and adolescence (29).

\section{Genetic influences}

Approximately $8 \%$ of the genetic component of obesity is chared with asthma (23). In fact, specific regions of the human genome (such as chromosomes 5q, 6, 11q13 and $12 q$ ) have been identified as related to both asthma and obesity. Chromosome $5 \mathrm{q}$ contains genes ADRB2 and $\mathrm{NR} 3 \mathrm{C} 1$. ADRB2, the gene that codes for the adrenergic $\beta_{2}$ receptor, influences sympathetic nervous system activity and is important in regulating not only the airway tone but also the resting metabolic rate (21). Polymorphisms in the $\beta 2$-adrenergic receptor, which is located in the chromosome 5q31-q32, have been associated with different asthma phenotypes, different levels of severity, and a response to $\beta$-agonists (9). NR3C1, which codes for the glucocorticoid receptor, participates in the modulation of inflammation in asthma and in obesity (8). Several studies have found associations between the $308-\mathrm{G} / \mathrm{A}$ polymorphism of the TNF- $\alpha$ gene (TNF, 6p21,3) and both asthma and obesity. The Ncol variant ine the lymphotoxin-A gene (LTA, 6p21,3), interacting with the 308-G/A polymorphism of the TNF- $\alpha$ has been associated with various asthma-related phenotypes, whereas the $\mathrm{T} 60 \mathrm{~N}$ polymorphism has been associated with waist circumference and other phenotypes of the metabolic syndrome (23). Chromosome 11q13 contains the genes for the uncoupling proteins UCP2 and UPC3, and the low affinity immunoglobulin E receptor. The UCP2 and UPC3 proteins influence resting metabolism, but not in asthma (8). In contrast, the receptor of low-affinity $\operatorname{IgE}$ forms part of the inflammatory response of the TH2 cells, whose levels increase in asthma, but not in obesity (9). Lastly, chromosome $12 \mathrm{q}$ contains genes for inflammatory cytokines associated both with asthma (e.g., IFN- $\gamma$, LTA4H, nitric oxide synthase-1) and with obesity (e.g., STAT6, insulin-like growth factor, CD36L1) (8). Finally, several variants in the vitamin D receptor gene (VDR, 12q13) have been associated with asthma-related phenotypes (23).

\section{Adipose tissue macrophages (ATMs)}

$\mathrm{F} 4 / 80^{+} \mathrm{CD} 11 \mathrm{~b}^{+} \mathrm{CD} 11 \mathrm{c}^{+}$macrophages accumulate in the fat with diet-induced obesity. M1 or "classically activated" macrophages are induced by proinflammatory mediators such as LPS and IFN- $\gamma$. M1 macrophages have enhanced proinflammatory cytokine production (TNF- $\alpha$, IL-6, IL-12) and generate reactive oxygen species such as NO via activation of iNOS (NOS2) (26). All of these cytokines have been implicated in many aspects of the airway pathology in asthma. ATMs from lean mice express markers of alternatively activated macrophages M2 or "alternatively activated" macrophages are generated in vitro by exposure to IL-4 and IL-13. M2 macrophages have low proinflammatory cytokine expression and instead generate high levels of antiinflammatory cytokines IL-10 and IL-1 decoy receptor. Additionally, arginase production is increased in M2-polarized macrophages. This enzyme blocks iNOS activity by a variety of mechanisms, including competing for the arginine substrate that is required for NO production (26). Recent studies suggest the role of arginase in ethiopatogenesis of bronchial asthma not only by influencing the nitric oxide prodution but also in chronic changes through the syntesis of polyamines.

\section{Hormonal factors}

The adipokine leptin is a potential new mediator for bronchial epithelial homeostasis (6). It remains unclear however, if leptin is in the pathway of obesity-asthma relationship and if it plays a distinctive role in asthma in obese vs. non-obese subjects. Since leptin is in a positive feedback loop with the pro-inflammatory cytokines such as TNF- $\alpha$, there is a pos- 
sibility that leptin is involved as a regulatory rather than an etiologic mechanism of asthma development. Weight loss is associated with decreased circulating leptin concentration in children (28). Leptin seems to play a fundamental role in inflammation in obese subjects: it possesses considerable structural homology with long-chain cytokines such as IL-6, and is capable of regulating the proliferation and activation of T cells, promoting angiogenesis, and recruiting activated monocytes and macrophages. Furthermore, leptin is important for the normal development of the lung, as it is a critical mediator in the differentiation between lipofi broblasts and fibroblasts and in the synthesis of lung surfactant (9). Leptin also acts on the sympathetic nervous system, specifically by activating the metabolism of brown fat. Both the sympathetic nervous system and brown fat regulate resting metabolism, but the sympathetic nervous system is also crucial in controlling of the airway tone and diameter- important markers in asthma. Leptin plasma levels have been positively correlated with body fat (8). Leptin resistance is commonly observed in obese patients, who can suffer from obesity-related asthma (19). Adipose tissue produces a number of mediators, termed adipokines, which have significant metabolic effects. One of these adipokines, adiponectin, is actually decreased in the obese. Low adiponectin levels have also been associated with asthma in population studies (10). In human subjects and in animals, adiponectin mRNA expression in adipocytes decreases in obesity and increases again with weight loss, and plasma adiponectin levels are inversely related to body mass index. In contrast, levels of most other adipokines, including leptin, resistin, and inflammatory cytokines, such as TNF- $\alpha$, increase with obesity. Whereas the primary metabolic effects of adiponectin are on glucose regulation and fatty acid metabolism, adiponectin is also anti-inflammatory. Adiponectin inhibits inflammatory gene expression in a variety of cell types, inhibits or modulates nuclear factor $\mathrm{kB}(\mathrm{NF}-\mathrm{kB})$ and extracellular signal-regulated kinase activation, and augments expression of anti-inflammatory genes, including the IL-1 receptor antagonist gene (36). We know that the enzyme aromatase, which is responsible for converting androgens into estrogens, is present in adipose tissue. In obesity, the production of estrogens is generally increased and this is associated with early menarche in women and delay in the onset of puberty in men (9). Obesity also decreases progesterone levels (Hernandes Garzia et al., 1999) and progesterone potentiates airway smooth muscle (ASM) relaxation (Foster et al., 1983) (34).

\section{Gender differences}

Several recent cross-sectional studies have documented a significant association between BMI and asthma in women but not in men. In contrast to the findings for adults, associations between obesity and asthma are inconsistent for children and adolescents. Some studies demonstrated that BMI was positively associated with wheezing and bronchial hyper-responsiveness in girls but not in boys, whereas another study found BMI to be associated with asthma in both boys and girls. One plausible hypothesis is that female sex hormones play an important role in the etiology of asthma and that these hormones are influenced by obesity. Progesterone upregulates beta-2 receptors. One hypothesis is that obesity reduces progesterone levels, which reduces beta- 2 adrenoreceptor function, which in turn reduces bronchial smooth muscle relaxation. BMI may not be an equivalent measure of fatness in men and women. The fact that men tend to have more muscle mass and women more fat mass may also contribute to the apparent gender-specific relation between obesity and asthma (17).

\section{Asthma severity and obesity}

The prevalence of obesity increases with increasing asthma severity in adults. The association of asthma severity with obesity suggests that obesity may be a potentially modifiable risk factor for asthma or asthma-like symptoms (1).

\section{Other comorbidities}

Cholesterol has been shown to have a complex influence on inflammation (13). High fat meals, which lead to significant increases in total cholesterol, and especially triglycerides, increase exhaled NO (Rosenkranz et al., 2010). This suggests that high fat diet can contribute to chronic inflammatory diseases of the airways and lungs (33). A recent meta-analysis of 20 studies reported a positive association between increasing body mass index (BMI) and the presence of gastro-oesophaegal reflux disease (GORD) within the USA (3). Changes in gastrooesophageal anatomy and physiology caused by obesity may explain the association. These include an increased prevalence of esophageal motor disorders, diminished lower esophageal sphincter pressure, the development of a hiatal hernia, and increased intragastric pressure (14). Asthma could arise as a result of acid reflux via two possible mechanisms: damage to the pulmonary tree after direct exposure to acid refluxate (reflux theory); or through bronchial constriction as a result of the stimulation of vagal nerve endings in the oesophagus (reflex theory).In addition, cough and increased respiratory effort may exacerbate GORD by bringing about an increased pressure gradient across the lower oesophageal sphincter (16). Morbidly obese asthma patients have a higher degree of insulin resistance compared to morbidly obese non-asthma patients (2). Levels of the vascular peptide endothelin-1 (ET-1) are significantly elevated in obesity (12). Endothelins are proinflammatory, profibrotic, broncho- and vasoconstrictive peptides which play an important role in the development of airway inflammation and remodeling in asthma (39).

\section{Conclusions}

Because of the increase in the prevalence and comorbidity of obesity and asthma in the population, we have to be 
interested in understanding of their relationship. Numerous studies have pointed out the associations in the etiopathogenesis. These associations need to be taken into account when performing diagnostical and therapeutical management of the patient. It is important to realize the possible complications caused by simultaneous occurrence of obesity and asthma in patients, for example the differences in drug metabolism in the obese. This knowledge can lead to the formation of new therapeutical guidelines for the obese. In general, obesity may worsen asthma control, therefore obese children as well as their parents should be motivated to reduce body weight. A multidisciplinary approach is needed, consisting of cooperation among general practitioners, specialists in allergology and pneumology, nutritional therapists and child psychologists.

\section{Acknowledgment}

This work was supported by the project "Centre of Experimental and Clinical Respirology II" co-financed from EU sources and European Regional Development Fund.

\section{References}

1. Akerman, MJH, Calacanis, CM, Madsen, MKM. Relationship Between Asthma Severity and Obesity. Journal of Asthma 2005; 41(5):521-526.

2. Al-Shawwa BA, Al-Huniti NH, DeMattia L, Gershan W. Asthma and Insulin Resistance in Morbidly Obese Children and Adolescents. Journal of Asthma 2007; 44 (6):469-473

3. Ayazi S, Hagen JA, Chan LS, et al. Obesity and gastroesophageal reflux: quantifying the association between body mass index, esophageal acid exposure, and lower esophageal sphincter status in a large series of patients with reflux symptoms.J Gastrointest Surg 2009; 13(8):1440-7.

4. Beuther D, Sutherland E. Overweight, Obesity, and Incident Asthma: A Metaanalysis of Prospective Epidemiologic Studies, American Journal of Respiratory and Critical Care Medicine 2007; 175:661-666.

5. Branca F, Nikogosian H, Lobstein T. The challenge of obesity in the WHO European Region and the strategies for response. World Health Organization, $2007 \cdot 1$

6. Bruno A, Pace E, Chanez P, et al. Leptin and leptin receptor expression in asthma J Allergy Clin Immuno 2009; 124(2):230-7.

7. Carraro, Cogo PE, Isak I, et al. EIA and GC-MS analysis of 8-isoprostane in EBC of children with problematic asthma. Eur Respir J. (released 6/11/2009). (Accessed May 24, 2010, at http://www.erj.ersjournals.com/cgi/content/abstract 09031936.00074909v1)

8. Castro-Rodríguez JA. Relationship between obesity and asthma. Arch Bronconeumol 2007; 43(3):171-5.

9. Delgado J, Barranco P, Quirce S. Obesity and asthma. J Investig Allergol Clin Immunol 2008; 18(6):420-425.

10. Dixon AE. Adipokines and asthma. Chest 2009; 135:255-256

11. Enfield K, Shim M, Sharma G. Asthma, obesity and type 2 diabetes - mechanisms, management and prevention, Diabetes voice 2009; 54(2):30-33.

12. Eriksson AM, Harmelen V, Stenson BM. Endothelin-1 stimulates human adipocyte lipolysis through the ETA receptor. International Journal of Obesity 2009; 33:67-74

13. Fessler MB, Massing MW, Spruell B, et al. Novel relationship of serum cholesterol with asthma and wheeze in the United States. J Allergy Clin Immunol, 2009; 124(5):967-74.

14. Friedenberg FK, Xanthopoulos M, Foster GD, Richter JE. The Association Be- tween Gastroesophageal Reflux Disease and Obesity. The American Journal of Gastroenterology 2008; 103:2111-2122.

15. Greenberg AS, Obin AS. Obesity and the role of adipose tissue in inflammation and metabolism. American Journal of Clinical Nutrition 2006; 83(2):461-465.

16. Havemann BD, Henderson CA, El-Serag HB. The association between gastro-oesophageal reflux disease and asthma: a systematic review. Gut 2007; 56:1654-1664.

17. Chen Y, Dales R, Tang M, Krewski D. Obesity May Increase the Incidence of Asthma in Women but Not in Men: Longitudinal Observations from the Canadian National Population Health Surveys. Am J Epidemiol 2002; 155(3): 191-197.

18. Kim JH, Ellwood PE, Asher MI. Diet and asthma: looking back, moving forward. Respiratory Research 2009, 10:49doi:10.1186/1465-9921-10-49.

19. Kling J. ACAAI 2008: Increased Leptin Levels Linked to Asthma, Medscape Medical News (released 14/11/2008). (Accessed April 21, 2010 at http://www .medscape.com/viewarticle/583629).

20. Krasničanová H. Pediatrická auxologie - Datový standard MZČR. (Assessed June 25, 2010 at http://ciselniky.dasta.mzcr.cz/CD_DS3/hypertext/HKAAD.htm).

21. Lee H J, Moore JH, Park S. Genetic interactions model among Eotaxin gene polymorphisms in asthma. Journal of Human Genetics 2008; 53(10):867-875.

22. Lehrke S, Laessle RG. Adipositas im Kindes- und Jugendalter. 2nd ed. Springer Medizin Verlag Heidelberg 2009; 1:3.

23. Litonjua AA, Gold DR. Asthma and obesity: Common early-life influences in the inception of disease 2008; 121(5): 1075-1084

24. Loerbroks A, Apfelbacher Ch J, Amelang M, Stürmer T. Obesity and Adult Asthma: Potential Effect Modification by Gender, But Not by Hay Fever. Annals of Epidemiology 2008; 18(4):283-289.

25. Löfgren P, Harmelen V, Reynisdottir S. Secretion of Tumor Necrosis Factor Shows a Strong Relationship to Insulin-Stimulated Glucose Transport in Human Adipose Tissue. Diabetes 2000; 49:688-692.

26. Lumeng NC, Bodzin JL, Saltiel AR. Obesity induces a phenotypic switch in adipose tissue macrophage polarization. J. Clin. Invest 2007; 117(1):175-184.

27. Ma Z, Paek D, Oh CK. Plasminogen activator inhibitor-1 and asthma: role in the pathogenesis and molecular regulation. Clinical \& Experimental Allergy 2009; 39(8):1136-1144.

28. Mai XM, Chen Y, Krewski D.Does leptin play a role in obesity-asthma relationship? Pediatr Allergy Immunol 2009; 20(3):207-12.

29. Miller RL, Ho S. Enviromental epigenetics and asthma. American Journal of Respiratory and Critical Care Medicine 2008, 177:567-573.

30. Morisset A, Huot C, Légaré D, Tchernof A. Circulating IL-6 Concentrations and Abdominal Adipocyte Isoproterenol-stimulated Lipolysis in Women. Obesity 2008; 16(7):1487-1492.

31. Mosen MD, Schatz M, Magid DJ, Camargo CA. The relationship between obesity and asthma severity and control in adults. J Allergy Clin Immunol 2008; 122(3):507-11

32. Pakhale S, Doucette S, Vandemheen K, et al. A comparison of obese and nonobese asthmatics: Exploring an asthma-obesity interaction. Chest (released 10/2/2010). (Accessed May 12, 2010, at: http://www.ncbi.nlm.nih.gov/pubmed /20154078?itool=EntrezSystem2.PEntrez.Pubmed.Pubmed_ResultsPanel.Pubmed RVDocSum\&ordinalpos $=2$ ).

33. Rosenkranz SK, Townsend DK, Steffens SE, Harms CA. Effects of a high-fat meal on pulmonary function in healthy subjects. Eur J Appl Physiol 2010; 109(3): 499-506.

34. Shore SA, Johnston RA. Obesity and Asthma. Pharmacology and Therapeutics 2006; 110:83-102.

35. Shore SA. Obesity and asthma: Possibe mechanisms. J Allergy Clin Immunol. 2008; 121(5):1087-1092.

36. Shore SA, Terry RD, Flynt L, Xu A, Hug Ch. Adiponectin attenuates allergeninduced airway inflammation and hyperresponsiveness in mice. J Allergy Clin Immunol 2006; 118:389-95.

37. Schwarz SM, Freemark M. Obesity, 2010, (updated 13/4/2010). (Assessed April 24, 2010 at http://emedicine.medscape.com/article/985333-overview).

38. Wirl Ch, Puklová V. Prevalence of asthma and allergies in children, FACT SHEET NO. 3.1, 2007, http://www.euro.who.int/Document/EHI/ENHIS Factsheet 3 1.pdf

39. Zietkowski Z, Skiepko R, Tomasiak MM, Bodzenta-Lukaszyk A. Endothelinin exhaled breath condensate of allergic asthma patients with exercise-induced bronchoconstriction. Respir Res. 2007; 31(8):76.

Received: 07/07/2010

\section{Corresponding author:}

Accepted in revised form: 25/02/2011

Jana Kryštofová, MD., Department of Pediatrics, Jessenius Medical Faculty, Comenius University in Bratislava, Kollárova 2, 03659 Martin, Slovak Republic; e-mail: krystofova1@india.com 